\title{
Preliminary Survey on the Co-occurrence of DON and T2+HT2 Toxins in Durum Wheat in Italy
}

\author{
G. Aureli ${ }^{1 *}$, T. Amoriello ${ }^{2}$, A. Belocchi ${ }^{1}$, M.G. D’EGidio ${ }^{1}$, M. Fornara ${ }^{1}$, \\ S. MELloni ${ }^{1}$ and F. QuARANTA ${ }^{1}$ \\ ${ }^{1}$ Consiglio per la Ricerca e la sperimentazione in Agricoltura, Unità di ricerca per la valorizzazione \\ qualitativa dei cereali (CRA-QCE), Via Cassia n. 176, 00191 Rome, Italy \\ ${ }^{2}$ Consiglio per la Ricerca e la sperimentazione in Agricoltura, Centro di ricerca per gli alimenti \\ e la nutrizione (CRA-NUT), Via Ardeatina 546, 00178 Rome, Italy
}

(Received 27 June 2014; Accepted 24 November 2014)

\begin{abstract}
This study was carried out to determine the co-occurrence of deoxynivalenol (DON) and the sum of T2 and HT2 toxins in durum wheat samples belonging to eight cultivars grown in a national network experimental trials over a three-year period (2011-2013). The effect of several factors (cultivar, year and cultivation area) affecting the occurrence of the two types of mycotoxins and their relationship with several agronomic and grain quality parameters were assayed by statistical analysis (GLZ). The results highlighted the different trend of incidence and contamination rate of the two types of mycotoxins in relation to the cropping year and to the growing examined areas. Year and its interaction with the cultivation area was the most important factor affecting the DON contamination, whereas genotype and its interaction with the year mainly influenced T2+HT2 toxins contamination rate. DON and T2+HT2 contamination levels were not significantly correlated with each other. The evidence that the two types of mycotoxins were differently related with several agronomic and grain quality parameters could be connected to the effects of the respective fungal disease on wheat plant.
\end{abstract}

Keywords: deoxynivalenol, T2, HT2, Fusarium, durum wheat

\section{Introduction}

Trichothecenes are a large group of chemically related toxic fungal compounds mainly produced by Fusarium spp. in cereal grains. These mycotoxins have multiple toxic effects on eukaryotic cells including inhibition of protein, DNA and RNA synthesis (Lemmens et al. 2005; Rocha et al. 2005; Lancova et al. 2008; Yazar and Omurtag 2008; Gauthier et al. 2013). Deoxynivalenol (DON) is the most common mycotoxin among the type B group of trichothecenes found at high concentration in cereals and mainly produced by F. graminearum and F. culmorum (Terzi et al. 2007; Häller et al. 2008; Miller 2008; Edwards 2009). The main features of DON on animals are constituted by an emetic effect (DON or "vomitoxin") and immunosuppressive effects also representing a risk for human health (SCF 2002; He et al. 2010; Pestka and Smolinski 2005; Maresca 2013). T2 and

* Corresponding author; E-mail: gabriella.aureli@entecra.it; Fax: +39 0636306022 
HT2 toxins belong to the type A group of trichothecenes known as the most toxic members of this group of mycotoxins. The T2 toxin is rapidly transformed to a large group of products, HT2 toxin resulting as the major metabolite with equivalent toxicity, and the sum of T2 and HT2 was considered in the determination (Edwards et al. 2009; EFSA 2011). T2 and HT2 toxins are reported to be implicated in human Alimentary Toxic Aleukia (ATA) due to the consumption of contaminated grain (Wu et al. 2010). The main source of trichothecenes in the food chain is Fusarium-contaminated grain and for this reason Fusarium Head Blight (FHB or "scab") outbreak of cereal crops is of great interest. F. graminearum Schwabe and F. culmorum (WG Smith) are the most relevant species of fungi causing the FHB disease often determining both severe reduction of crop yield and production of fungal secondary metabolites (e.g. DON) in grains which are mainly influenced by environment, genotype and management practices (Pestka and Smolinski 2005; Rocha et al. 2005; Shephard 2008; Ván̆ová et al. 2008; Berthiller et al. 2009; Russel et al. 2010; Zain 2011). The susceptibility shown by durum wheat (Triticum durum Desf.) to the FHB disease is of particular concern in Italy due to the important role of this species in the "pasta" production. As regards fungi capable of producing T2 and HT2 toxins F. langsethiae is considered the main producer (Edwards et al. 2012). This species results closely related to F. sporotrichioides Scherb. and F. poae (Schmidt et al. 2004) and the same is known in Europe as grain contaminant of small grain cereals such as oats (the most susceptible type of cereal), barley and wheat. Moreover, the influence of temperature on infection, growth, and mycotoxin production by $F$. langsethiae and $F$. sporotrichioides (Nazari et al. 2014) and the distribution of T2 and HT2 in milling fractions (Pascale et al. 2011) were assayed on durum wheat. F. langsethiae was also identified on wheat in Italy (Infantino et al. 2007). Nowadays the approach to the problem mycotoxins in foods is mainly oriented on one side to improve prevention in field, and on the other one to assay the occurrence of simultaneous presence of different mycotoxins (e.g.: deoxynivalenol, T2 and HT2 toxins, nivalenol, etc.). The attention of the European Community is focusing more and more on that direction through the recently adopted Recommendation (2013/165/UE; EFSA 2011) concerning the "indicative" levels for the sum of T2 and HT2 in different matrices: for unprocessed durum wheat the maximum level is $100 \mu \mathrm{g} / \mathrm{kg}$. The same Recommendation reports also an invitation to the European countries to ascertain the co-occurrence of T2 and HT2 and other toxins from Fusarium spp. assessing the degree of concentration. Therefore, today from the Fusarium toxins belonging to the group of trichothecenes, only for deoxynivalenol maximum limits were set in cereals and cereal products (EC Regulation 1881/2006, EC Regulation 1126/2007) which are of $1750 \mu \mathrm{g} / \mathrm{kg}$ in unprocessed durum wheat. The aim of this study was to investigate the co-occurrence of DON and the sum of T2 and HT2 (T2+HT2) toxins in durum wheat crops in Italy with regard to the following topics: 1 ) the levels of DON and T2+HT2 contamination in unprocessed kernels of durum wheat also considering the influence of several important factors (cultivar, year and cultivation area); 2) the relationships between the two aforesaid A and B types of trichothecenes detected and their correlation with several agronomic/grain quality parameters. 


\section{Materials and Methods}

The overall 240 durum wheat kernel samples were collected during the 2011-2013 threeyear period within the Italian durum wheat network experimental trials (Quaranta et al. 2013). A total of 10 locations were included in this study, grouped in five macro-areas (Fig. S1*): North, Centre-East, Centre-West, South and Sicily (only one location). A number of 8 cultivars were evaluated every year (Claudio, Duilio, Dylan, Iride, Kanakis, Ramirez, Sculptur and Simeto). Each experimental trial was carried out according to a randomized complete block experimental design (RCBD) with three replications $\left(10 \mathrm{~m}^{2}\right.$ plots); this experimental protocol was the same both for year and location. Agronomic traits were determined at plot level: after harvesting, grain was air-cleaned and weighed to determine grain yield ( $\mathrm{t} / \mathrm{ha}$ ), corrected to $13 \%$ of moisture content (GY). On the samples test-weight $(\mathrm{TW})(\mathrm{kg} / \mathrm{hL})$ (FOSS Infratec ${ }^{\mathrm{TM}} 1241$ Grain Analyzer, Sweden) and thousand-kernels weight (TKW) (g) (Pfeuffer Contador GmbH, Germany) were determined. Subsequently grains from the three replication plots were bulked and a representative whole grain subsample was milled (particle size $\leq 1 \mathrm{~mm}$ ) using Cyclotec 1093 (FOSS, Sweden). The whole meal was used for protein content determination ( $\%$ d.m.) by Dumas method (Leco FP 428, Germany). The same whole milled grain subsamples were submitted to the mycotoxins analyses by Enzyme-Linked Immuno-Sorbent Assay (ELISA). DON determination was made on acqueous (distilled water) extract of matrix according to the Ridascreen ${ }^{\circledR}$ DON method with LOD of $18.5 \mu \mathrm{g} / \mathrm{kg}$ (R-Biopharm AG, Germany). The analyses were performed using the Basic Robotic Immunoassay Operator (BRIO, SEAC, Radim Group, Italy). The T2+HT2 detection was carried out on methanolic extracts of matrix according to the instructions of Veratox ${ }^{\circledR}$ T2/HT2 toxin method (Neogen, USA), with LOD of $25.0 \mu \mathrm{g} / \mathrm{kg}$. The absorbance values were read using Sirio-S Microplate Reader (SEAC, Radim Group, Italy) and concentration data were obtained by the use of RIDA ${ }^{\circledR}$ Soft Win software (R-Biopharm AG, Germany). Distilled water was obtained from Water Purification System Zeener Power I (Human Corporation, Korea) and methanol (analytical grade) was supplied by Sigma (Sigma-Aldrich, UK) (Fig. S1).

In order to statistically analyze the data, samples with mycotoxins value below LOD were equalized to zero (Tittlemier et al. 2013). Descriptive statistics, including mean, standard deviation (SD), minimum (Min) and maximum (Max) value, $25^{\text {th }}$ percentile (Q1), median (Q2), 75 ${ }^{\text {th }}$ percentile (Q3) and 95 th percentile (P95) were calculated for DON and T2+HT2. The data were graphically reported by box plots concerning $25-75 \%$ range, median, not outliers range, both suspected outlier and outlier data. Generalized linear model (GLZ) was applied to assess the influence of three factors (cultivar, year and cultivation area) and all their two-way interactions on DON and T2+HT2 contamination. We assumed the response variable $\mathrm{Y}_{\mathrm{A}, \mathrm{B}}(\mathrm{DON}$ or $\mathrm{T} 2+\mathrm{HT} 2)$ had a Poisson distribution and the logarithm of its expected value $\mathrm{E}(\mathrm{Y})$ could be modelled by a linear combination of unknown parameters. Poisson regression models were GLZ with the logarithm as the canonical link function and the Poisson distribution function. The statistical model was:

\footnotetext{
* Further details about the Electronic Supplementary Material (ESM) can be found at the end of the article.
} 


$$
\log \left(\mathrm{Y}_{\mathrm{A}, \mathrm{B}}\right)=\beta_{0}+\tau_{\mathrm{i}}+\delta_{1}+\zeta_{\mathrm{k}}+\tau_{\mathrm{i}} \cdot \delta_{1}+\tau_{\mathrm{i}} \cdot \zeta_{\mathrm{k}}+\delta_{\mathrm{l}} \cdot \zeta_{\mathrm{k}}+\varepsilon_{\mathrm{ilk}}
$$

where $\mathrm{Y}_{\mathrm{A}, \mathrm{B}}=\mathrm{DON}(\mathrm{A})$ or T2+HT2 (B) mycotoxins; $\beta_{0}=$ average effect common to all observations; $\tau_{\mathrm{i}}=$ cultivar $(\mathrm{CV}) ; \mathrm{i}=1, \ldots, 8$ (Claudio, Duilio, Dylan, Iride, Kanakis, Ramirez, Sculptur, Simeto); $\delta_{1}=$ year; $1=1, \ldots, 3 ;(1=2011,2=2012,3=2013) ; \zeta_{\mathrm{k}}=$ area; $\mathrm{k}=1, \ldots, 5$ (North, Centre-East, Centre-West, South, Sicily); $\varepsilon=$ error term. The goodness of fit of GLZ model could be based on the deviance statistic, approximated by a chi-square distribution. We used the log-likelihood value to measure the goodness of fit of the regression models. To assess association within DON and T2+HT2 mycotoxins and agronomic/grain quality variables (yield, test-weight, 1000-kernel weight, and protein content), Spearman's non-parametric correlation was used. Statistical significance levels for the correlation tests were set at $p<0.01(* *)$ and at $p<0.05(*)$.

\section{Results}

The diffusion of monitored mycotoxins during the three-year period was reported in Fig. S2 as percentage (incidence \%) of positive samples (concentration $\geq$ LOD). In the North it could be noted a high incidence of DON positive samples (from $79 \%$ to $100 \%$ ) and a general low incidence of T2+HT2 (from $4 \%$ to $29 \%$ ) with greater presence of DON and less diffusion of T2+HT2 in the year 2013. In Central Italy, where an exceptional amount of rain in the year 2013 occurred (Quaranta et al. 2013), a general heavy diffusion of both classes of mycotoxins was assayed. In the South lower incidence of DON (from $44 \%$ to $63 \%$ ) and no negligible presence of T2+HT2 (from 25\% to $44 \%$ ) were pointed out. Data referred to the unique field of Sicily showed no presence of T2+HT2 all over the threeyear period whereas DON incidence ranged from 0 to $63 \%$, even if corresponding to negligible concentration level (Fig. S2).

The different trend of DON and T2+HT2 toxins was also confirmed by the contamination level (mean) of positive samples for each year especially in the North, where the highest value of DON (14452 $\mu \mathrm{g} / \mathrm{kg}$ ) was reached in the year 2013 (Fig. S3). In Central Italy (both in East and West sides) the average levels of DON for positive samples were lower than $500 \mu \mathrm{g} / \mathrm{kg}$, with a maximum value of $1080 \mu \mathrm{g} / \mathrm{kg}$ in Centre-West during 2011. In the South and Sicily, DON levels were always below $150 \mu \mathrm{g} / \mathrm{kg}$ (Fig. S3a). A clear presence of T2+HT2 was found in Centre-East (average values from $67 \mu \mathrm{g} / \mathrm{kg}$ to 106 $\mu \mathrm{g} / \mathrm{kg}$ ) and in the South (average values from $33 \mu \mathrm{g} / \mathrm{kg}$ to $96 \mu \mathrm{g} / \mathrm{kg}$ ) (Fig. S3b). These toxins were not detected in the Central West side only in the year 2013, whereas in the field of Sicily all over the three years. Although the conditions for the in vivo production of T2 and HT2 toxins in cereals are not entirely clear, data collected in several European countries outline that the occurrence of wet summer could represent a more favourable condition for the production of the main Fusarium-toxins (e.g.: DON). On the contrary T2 and HT2 toxins reach high levels in warm and dry seasons (Langseth and Rundberget 1999; Hietaniemi et al. 2004; Imathiu et al. 2013). These weather conditions generally occur both in late spring and in summer seasons in the Centre-South of Italy and in Sicily. Therefore, even though the implicated Fusarium species were not assayed in this survey by using microbiological and/or molecular methods from the milled samples, the low 
presence of T2+HT2 toxins in the North overall the three-year period, especially in the wettest year 2013, and the absence of the same toxins in the Centre-West in the same rainy year suggest the absence of suitable conditions for development of T2+HT2 toxins producer fungi and/or the competition of these types of fungi with other Fusarium species (e.g.: F. graminearum). Limited to the North area, an opposite trend between DON and T2+HT2 emerged. The field considered in Sicily showed the lowest mycotoxins risk for durum wheat, according to previous surveys on DON contamination (Aureli et al. 2009; Quaranta et al. 2010). Moreover, the data concerning the incidence and the contamination levels of T2+HT2 toxins in the central-southern areas of Italy resulted in agreement with the presence of $F$. langsethiae previously reported (Santori et al. 2010) (Fig. S3).

Tables 1, 2 and 3 showed some descriptive statistics (mean, standard deviation, minimum, maximum, 25 th percentile Q1, median Q2, 75 th percentile Q3 and $95^{\text {th }}$ percentile P95) of DON and T2+HT2 toxins with regard to cultivar, year and cultivation area, respectively. With regard to cultivar, the box plot of DON (Fig. S4a) and T2+HT2 (Fig. S4b) concentrations are reported. The distribution referred to cultivar is strongly asymmetric. The T2+HT2 values were distributed close to zero with the exception of Sculptur, Simeto and Duilio and the last two cultivars were also sensitive to the DON (Table 1, Fig. S4). Particularly, Simeto showed the greatest $75^{\text {th }}$ percentile values both of DON and T2+HT2 (428 and 77 ppb, respectively). On the contrary the cultivar Ramirez achieved the best performance with regard both to the T2+HT2 (P95 < LOD) and DON $(\mathrm{P} 95<773 \mu \mathrm{g} / \mathrm{kg})$ occurrence. On the whole the DON values were distributed over a wide range: from $<$ LOD to $1080 \mu \mathrm{g} / \mathrm{kg}$ in 2011, from $<\mathrm{LOD}$ to $2799 \mu \mathrm{g} / \mathrm{kg}$ in 2012 and from < LOD to $14452 \mu \mathrm{g} / \mathrm{kg}$ in 2013 (Table 2). T2+HT2 contamination was similar all

Table 1. Descriptive statistics: number of samples $(\mathrm{N})$, mean $(\mu \mathrm{g} / \mathrm{kg})$, standard deviation (SD), minimum $(\mu \mathrm{g} / \mathrm{kg})$, maximum $(\mu \mathrm{g} / \mathrm{kg}), 25^{\text {th }}$ percentile Q1, median Q2, 75 $5^{\text {th }}$ percentile Q3 and $95^{\text {th }}$ percentile P95 of DON and T2+HT2 toxins contamination by cultivar. Limit of detection (LOD) $=18.5 \mu \mathrm{g} / \mathrm{kg}$ for DON and $25.0 \mu \mathrm{g} / \mathrm{kg}$ for T2+HT2

\begin{tabular}{|l|c|c|c|c|c|c|c|c|c|c|}
\hline Cultivar & Toxin & $\mathrm{N}$ & Mean & SD & Min & Max & Q1 & Q2 & Q3 & P95 \\
\hline \multirow{2}{*}{ Claudio } & DON & 30 & 557 & 1957 & $<$ LOD & 10704 & 21 & 78 & 179 & 2036 \\
& T2+HT2 & 30 & $<$ LOD & - & $<$ LOD & 161 & $<$ LOD & $<$ LOD & $<$ LOD & 84 \\
\hline \multirow{2}{*}{ Duilio } & DON & 30 & 518 & 1562 & $<$ LOD & 8496 & $<$ LOD & 103 & 385 & 2129 \\
& T2+HT2 & 30 & $<$ LOD & - & $<$ LOD & 211 & $<$ LOD & $<$ LOD & 35 & 101 \\
\hline \multirow{2}{*}{ Dylan } & DON & 30 & 272 & 577 & $<$ LOD & 2900 & 22 & 52 & 345 & 1272 \\
& T2+HT2 & 30 & $<$ LOD & - & $<$ LOD & 153 & $<$ LOD & $<$ LOD & $<$ LOD & 85 \\
\hline \multirow{2}{*}{ Iride } & DON & 30 & 313 & 876 & $<$ LOD & 4713 & $<$ LOD & 82 & 152 & 1373 \\
& T2+HT2 & 30 & $<$ LOD & - & $<$ LOD & 103 & $<$ LOD & $<$ LOD & $<$ LOD & 100 \\
\hline \multirow{2}{*}{ Kanakis } & DON & 30 & 328 & 746 & $<$ LOD & 3275 & $<$ LOD & 96 & 221 & 2610 \\
& T2+HT2 & 30 & $<$ LOD & - & $<$ LOD & 64 & $<$ LOD & $<$ LOD & $<$ LOD & 41 \\
\hline \multirow{2}{*}{ Ramirez } & DON & 30 & 179 & 344 & $<$ LOD & 1755 & $<$ LOD & 48 & 242 & 773 \\
& T2+HT2 & 30 & $<$ LOD & - & $<$ LOD & 72 & $<$ LOD & $<$ LOD & $<$ LOD & $<$ LOD \\
\hline \multirow{2}{*}{ Sculptur } & DON & 30 & 271 & 690 & $<$ LOD & 2799 & $<$ LOD & 50 & 132 & 2744 \\
& T2+HT2 & 30 & 28 & 43 & $<$ LOD & 185 & $<$ LOD & $<$ LOD & 47 & 115 \\
\hline \multirow{2}{*}{ Simeto } & DON & 30 & 791 & 2623 & $<$ LOD & 14452 & 24 & 165 & 428 & 2231 \\
& T2+HT2 & 30 & 52 & 65 & $<$ LOD & 212 & $<$ LOD & $<$ LOD & 77 & 178 \\
\hline
\end{tabular}


Table 2. Descriptive statistics: number of samples $(\mathrm{N})$, mean $(\mu \mathrm{g} / \mathrm{kg})$, standard deviation (SD), minimum ( $\mu \mathrm{g}$ / $\mathrm{kg})$, maximum $(\mu \mathrm{g} / \mathrm{kg}), 25^{\text {th }}$ percentile Q1, median Q2, $75^{\text {th }}$ percentile Q3 and $95^{\text {th }}$ percentile P95 of DON and T2+HT2 toxins contamination by year. Limit of detection (LOD) $=18.5 \mu \mathrm{g} / \mathrm{kg}$ for DON and $25.0 \mu \mathrm{g} / \mathrm{kg}$ for $\mathrm{T} 2+\mathrm{HT} 2$

\begin{tabular}{|c|c|c|c|c|c|c|c|c|c|c|}
\hline Year & Toxin & $\mathrm{N}$ & Mean & SD & Min & Max & Q1 & Q2 & Q3 & P95 \\
\hline \multirow{2}{*}{2011} & DON & 80 & 147 & 219 & $<$ LOD & 1080 & $<$ LOD & 52 & 183 & 683 \\
& T2+HT2 & 80 & $<$ LOD & - & $<$ LOD & 185 & $<$ LOD & $<$ LOD & $<$ LOD & 87 \\
\hline \multirow{2}{*}{2012} & DON & 80 & 278 & 597 & $<$ LOD & 2799 & $<$ LOD & 50 & 223 & 2083 \\
& T2+HT2 & 80 & 26 & 48 & $<$ LOD & 212 & $<$ LOD & $<$ LOD & 35 & 157 \\
\hline \multirow{2}{*}{2013} & DON & 80 & 786 & 2264 & $<$ LOD & 14452 & 33 & 133 & 364 & 3994 \\
& T2+HT2 & 80 & $<$ LOD & - & $<$ LOD & 174 & $<$ LOD & $<$ LOD & $<$ LOD & 94 \\
\hline
\end{tabular}

over the three-year period even if in 2012 the greatest values were obtained (mean, max, Q3 and P95). Northern Italy was more sensitive to DON occurrence than the other areas, whereas the Centre-East to T2+HT2 toxins occurrence (average value equal to $45 \mu \mathrm{g} / \mathrm{kg}$ ), followed by the South (average value equal to $24 \mu \mathrm{g} / \mathrm{kg}$ ) (Table 3 ).

The results of the GLZ analysis concerning the effect of cultivar, year and cultivation area on DON and T2+HT2 contamination degrees (Table 4) showed that all of them were highly significant $(p<0.0001)$ whether as single factors or in the two-way interactions. Year $\left(\chi^{2}=24387, p<0.0001\right)$, cultivation area $\left(\chi^{2}=16234, p<0.0001\right)$ and their interaction $\left(\chi^{2}=16259, p<0.0001\right)$ were the most important factors which strongly affected DON occurrence. The genotype, although statistically significant $\left(\chi^{2}=25, p<0.0001\right)$, showed a low influence on DON, while cultivar had the highest influence on T2+HT2 contamination $\left(\chi^{2}=158, p<0.0001\right)$. For T2+HT2 toxins the most important interaction between cultivar and year was shown $\left(\chi^{2}=159, p<0.0001\right)$ while cultivation area seemed to have low influence on T2+HT2 toxins contamination degree $\left(\chi^{2}=38, p<0.0001\right)$.

Spearman's non-parametric correlation among DON and T2+HT2 toxins concentrations and the other kernel traits (yield, test weight, 1000-kernel weight, and protein con-

Table 3. Descriptive statistics: number of samples $(\mathrm{N})$, mean $(\mu \mathrm{g} / \mathrm{kg})$, standard deviation (SD), minimum $(\mu \mathrm{g} / \mathrm{kg})$, maximum $(\mu \mathrm{g} / \mathrm{kg}), 25^{\text {th }}$ percentile Q1, median Q2, 75 P95 of DON and T2+HT2 toxins contamination by cultivation area. Limit of detection (LOD) $=18.5 \mu \mathrm{g} / \mathrm{kg}$ for DON and $25.0 \mu \mathrm{g} / \mathrm{kg}$ for T2+HT2

\begin{tabular}{|c|c|c|c|c|c|c|c|c|c|c|}
\hline Area & Toxin & $\mathrm{N}$ & Mean & SD & Min & Max & Q1 & Q2 & Q3 & P95 \\
\hline North & $\begin{array}{c}\text { DON } \\
\text { T2+HT2 }\end{array}$ & $\begin{array}{l}72 \\
72\end{array}$ & $\begin{array}{c}1070 \\
<\mathrm{OOD}\end{array}$ & 2386 & $\begin{array}{l}<\mathrm{LOD} \\
<\mathrm{LOD}\end{array}$ & $\begin{array}{c}14452 \\
178\end{array}$ & $\begin{array}{r}84 \\
<\mathrm{LOD}\end{array}$ & $\begin{array}{c}220 \\
<\mathrm{IOD}\end{array}$ & 814 & 4713 \\
\hline Centre-East & $\begin{array}{c}\text { DON } \\
\text { T2+HT2 }\end{array}$ & $\begin{array}{l}48 \\
48\end{array}$ & $\begin{array}{c}196 \\
45\end{array}$ & $\begin{array}{c}196 \\
59\end{array}$ & $\begin{array}{l}<\mathrm{LOD} \\
<\mathrm{LOD}\end{array}$ & $\begin{array}{l}752 \\
212\end{array}$ & $\begin{array}{c}31 \\
<\mathrm{LOD}\end{array}$ & $\begin{array}{c}143 \\
29\end{array}$ & $\begin{array}{c}317 \\
70\end{array}$ & $\begin{array}{l}583 \\
167\end{array}$ \\
\hline Centre-West & $\begin{array}{c}\text { DON } \\
\text { T2+HT2 }\end{array}$ & $\begin{array}{l}48 \\
48\end{array}$ & $\begin{array}{c}187 \\
<\text { LOD }\end{array}$ & $\begin{array}{c}224 \\
-\end{array}$ & $\begin{array}{l}<\mathrm{LOD} \\
<\mathrm{LOD}\end{array}$ & $\begin{array}{c}1080 \\
84\end{array}$ & $\begin{array}{c}41 \\
<\text { LOD }\end{array}$ & $\begin{array}{c}108 \\
<\text { LOD }\end{array}$ & $\begin{array}{c}244 \\
<\text { LOD }\end{array}$ & $\begin{array}{c}641 \\
62\end{array}$ \\
\hline South & $\begin{array}{c}\text { DON } \\
\text { T2+HT2 }\end{array}$ & $\begin{array}{l}48 \\
48\end{array}$ & $\begin{array}{c}26 \\
<\mathrm{LOD}\end{array}$ & $\begin{array}{l}36 \\
-\end{array}$ & $\begin{array}{l}<\text { LOD } \\
<\text { LOD }\end{array}$ & $\begin{array}{l}137 \\
185\end{array}$ & $\begin{array}{l}<\text { LOD } \\
<\text { LOD }\end{array}$ & $\begin{array}{l}<\text { LOD } \\
<\text { LOD }\end{array}$ & $\begin{array}{l}33 \\
44\end{array}$ & $\begin{array}{c}100 \\
88\end{array}$ \\
\hline Sicily & $\begin{array}{c}\text { DON } \\
\text { T2+HT2 }\end{array}$ & $\begin{array}{l}24 \\
24\end{array}$ & $\begin{array}{l}<\text { LOD } \\
<\text { LOD }\end{array}$ & - & $\begin{array}{l}<\mathrm{LOD} \\
<\mathrm{LOD}\end{array}$ & $\begin{array}{c}\quad 68 \\
<\text { LOD }\end{array}$ & $\begin{array}{l}<\text { LOD } \\
<\text { LOD }\end{array}$ & $\begin{array}{l}<\text { LOD } \\
<\text { LOD }\end{array}$ & $\begin{array}{c}21 \\
<\text { LOD }\end{array}$ & $\begin{array}{c}39 \\
<\text { LOD }\end{array}$ \\
\hline
\end{tabular}


Table 4. $\chi^{2}$ regression for two models referred to DON and $\mathrm{T} 2+\mathrm{HT} 2$ toxins $(\mu \mathrm{g} / \mathrm{kg})$

\begin{tabular}{|l|c|c|c|c|}
\hline \multirow{2}{*}{ Factor } & \multicolumn{2}{c|}{ DON } & \multicolumn{2}{c|}{ T2+HT2 } \\
\cline { 2 - 5 } & $\chi^{2}$ & $\operatorname{Pr}>\chi^{2}$ & $\chi^{2}$ & $\operatorname{Pr}>\chi^{2}$ \\
\hline $\mathrm{CV}$ & 25 & $<0.0001$ & 158 & $<0.0001$ \\
\hline Year & 24387 & $<0.0001$ & 97 & $<0.0001$ \\
\hline Area & 16234 & $<0.0001$ & 38 & $<0.0001$ \\
\hline $\mathrm{CV}^{*}$ Year & 25 & $<0.0001$ & 159 & $<0.0001$ \\
\hline $\mathrm{CV}^{*}$ Area & 12 & 0.0005 & 66 & $<0.0001$ \\
\hline Year*Area & 16259 & $<0.0001$ & 38 & $<0.0001$ \\
\hline
\end{tabular}

Note: $\mathrm{CV}=$ cultivar; Area $=$ cultivation area.

Table 5. Spearman's non-parametric correlation coefficient among agronomic/grain quality variables, DON and T2+HT2 concentrations $(\mu \mathrm{g} / \mathrm{kg})$

\begin{tabular}{|l|c|c|c|c|c|c|}
\hline Mycotoxin & DON & T2+HT2 & Yield & Test-weight & 1000 -kernel weight & Protein content \\
\hline DON & 1 & $0.098(\mathrm{~ns})$ & $0.117(\mathrm{~ns})$ & $-0.319(* *)$ & $0.020(\mathrm{~ns})$ & $0.314(* *)$ \\
\hline T2+HT2 & & 1 & $0.147(*)$ & $0.048(\mathrm{~ns})$ & $0.250(* *)$ & $0.057(\mathrm{~ns})$ \\
\hline
\end{tabular}

** Correlation is significant at the 0.01 probability level; *Correlation is significant at the 0.05 probability level. ns: not significant.

tent) are given in Table 5. No significant association between DON and T2+HT2 toxins was found. The DON concentration showed a positive correlation with the protein content $(\rho=0.314, p<0.01)$ and a negative correlation with the test-weight $(\rho=-0.319$, $p<0.01)$; a positive relationship between T2 + HT2 toxins and yield $(\rho=0.147, p<0.05)$ was found and lightly higher with 1000 -kernel weight $(\rho=0.250, p<0.01)$. On the whole the correlation between the mycotoxins concentration and agronomic/grain quality parameters showed a different trend for DON and T2+HT2 toxins. In fact the negative correlation rate $(\rho=-0.319, p<0.01)$ between DON and test-weight would suggest a damaged grain kernels related to the protein content (Boyacioğlu and Hettiarachchy 1995; Dexter et al. 1997; Nightingale et al. 1999).

\section{Discussion}

The results showed that year, cultivation area and their interaction were the most important factors which strongly affected DON occurrence in agreement with previous surveys on wheat (Edwards et al. 2009; Aureli et al. 2009). As regards T2+HT2 toxins the data obtained seemed to be in agreement with recent surveys carried out in other European countries which outlined the importance of the year in the accumulation of T2 and HT2 in cereals at least partly related to the warm and dry weather conditions but also in relation to varieties (Edwards 2009; van der Fels-Klerx and Stratakou 2010).

The positive correlation with protein content would be explained by a concentration effect in damaged kernel. Although no significant correlation was found between DON 
and yield and 1000-kernel weight, these preliminary results seemed at least partially in agreement with the effect caused by FHB attacks on grains (shrivelled kernels) when DON producers fungi, mainly $F$. graminearum and F. culmorum, are involved.

On the other hand, the significant and positive correlation of T2+HT2 toxins with the grain yield and the 1000-kernel weight seemed to suggest a general healthy kernel condition which substantially agrees with previous observations on the lack of clear disease and/or visual symptoms on cereal heads in field although the presence of $F$. langsethiae was confirmed (Imathiu et al. 2013; Opoku et al. 2013). In fact, this fungus is known for its inability to cause severe disease symptoms on cereals (e.g.: wheat and oat) without apparent loss of grain yield (Torp and Adler 2004; Imathiu et al. 2010; Divon et al. 2011). Nowadays the relation between grain characteristics and the presence of DON and $\mathrm{T} 2+\mathrm{HT} 2$ are not sufficient to draw comprehensive conclusions.

However, available data from the literature concerning various types of cereals (wheat, barley and oat) does not seem to show a positive correlation between the concentration levels of DON and T2+HT2 but rather a trend to mutual exclusion between the two types of mycotoxins. A sign of mutual exclusion among different types of mycotoxins is probably due to the competition and/or different environmental requirements of the different species of Fusarium mycotoxin producers (Barrier-Guillot 2009; Edwards 2009).

The coexistence of the two toxins in cereals, however, was already reported in other areas of northern Europe (Langseth and Rundberget 1999). Moreover, the impact of agronomic practices on the concentration of T2+HT2 in cereals has not been clearly identified but surveys carried out in some European countries revealed the influence on the F. langsethiae spreading and $\mathrm{T} 2+\mathrm{HT} 2$ production of some agronomic practices, such as presence of crop debris and minimum-tillage, in a way similar to the FHB disease (Imathiu et al. 2013). On the whole, this preliminary investigation on the co-occurrence of DON and T2+HT2 mycotoxins on durum wheat samples, collected in several growing areas of Italy over a three-year period, pointed out several aspects concerning their diffusion in the assayed growing areas.

The different trend of the incidence percentage and the contamination rate of the two types of mycotoxins were highlighted in relation to the cropping year and to the examined cultivation areas. The assayed cultivars showed different rates of sensibility to DON and T2+HT2 mycotoxins accumulation in grains, and this indication could suggest the opportunity to perform further investigations about this aspect within the durum wheat breeding programs. Among the environmental factors which were assayed, both year and its interaction with the cultivation area showed the main influence on DON contamination levels, whereas T2+HT2 toxins were mostly influenced by the cultivar and its interaction with the year. DON and T2+HT2 contamination rates were not significantly correlated and each type of these mycotoxins was differently related with several agronomic/grain quality parameters. The latter aspect might perhaps be connected to the behavior of the respective producing fungi on wheat plant with particular regard to the disease effects on grains. Further information about the relationship between the co-occurrence of DON and T2+HT2 toxins on durum wheat necessarily implies an in-depth investigation on the characteristics of competitiveness and/or adaptability to environmental conditions of the fungal species involved. 


\section{Acknowledgements}

The authors acknowledge M. Perenzin (CRA-SCV, S. Angelo Lodigiano - LO), P. Viola (Apsovsementi, Voghera - PV), A. De Montis (Co.Na.Se., Conselice - RA), R. Santilocchi (University of Ancona, Agugliano - AN), A. Petrini (CERMIS, Tolentino - MC), P. Bottazzi (Tuscany Region, Grosseto), P. Codianni (CRA-CER, Foggia and Calitri - AV), A. S. Frenda (University of Palermo) for carring out the field trials, and C. Cecchini and C. Ripa for technical support. This work was carried out in the frame of the project "MICOPRINCEM" supported by the Italian Ministry of Agricultural, Food and Forestry Policies and coordinated by the Agricultural Research Council (CRA).

\section{References}

Aureli, G., Belocchi, A., Pascale, M., Amoriello, T., D’Egidio, M.G., Desiderio, E. 2009. Progetto regionale MICOCER: Monitoraggio dei livelli di deossinivalenolo nella granella di frumento duro (Triticum durum Desf.). /MICOCER Project: Monitoring of the deoxynivalenol levels in durum wheat grain (Triticum durum Desf.)/. Rapporti ISTISAN 10/32:84-92.

Barrier-Guillot, B. 2009. T-2 and HT-2 in cereals in France. $6^{\text {th }}$ Fusarium Toxin Forum, 9-10 February 2009, Brussels, Belgium. www.micotossine.it/public/pag_542.pdf.

Berthiller, F., Schuhmacher, R., Adam, G., Krska, R. 2009. Formation, determination and significance of masked and other conjugated mycotoxins. Anal. Bioanal. Chem. 395:1243-1252.

Boyacioğlu, D., Hettiarachchy, N.S. 1995. Changes in some biochemical components of wheat grain that was infected with Fusarium graminearum. J. Cereal Sci. 21:57-62.

Commission Recommendation (2013/165/EU). Official J. of the European Union L. 91/12.

Commission Regulation (EC) No. 1126/2007. Official J. of the European Union L. 255/14.

Commission Regulation (EC) No. 1881/2006. Official J. of the European Union L. 364/5.

Dexter, J.E., Marchylo, B.A., Clear, R.M., Clarke, J.M. 1997. Effects of fusarium head blight on semolina milling and pasta-making quality of durum wheat. Cereal Chem. 74:519-525.

Divon, H.H., Razzaghian, J., Udnes-Aamont, H., Klemsdal, S.S. 2011. Fusarium langsethiae (Torp and Nirenberg), investigation of alternative infection routes in oats. Eur. J. Plant Pathol. 132:147-161.

Edwards, S.G., Imathiu, S.M., Ray, R.V., Back, M., Hare, M.C. 2012. Molecular studies to identify the Fusarium species responsible for HT-2 and T-2 mycotoxins in UK oats. Int. J. of Food Microbiology 156:168-175.

Edwards, S.G. 2009. Fusarium mycotoxin content of UK organic and conventional wheat. Food Addit. Contam. 26:496-506.

Edwards, S.G., Barrier-Guillot, B., Clasen, P-E., Hietaniemi, V., Pettersson, H. 2009. Emerging issues of HT-2 and T-2 toxins in European cereal production. World Mycotoxin J. 2:173-179.

EFSA 2011. Scientific opinion on the risk for animal and public health related to the presence of T-2 and HT-2 toxin in food and feed. EFSA J. 9:2481.

Gauthier, T., Waché, Y., Laffitte, J., Taranu, I., Saeedikouzehkonani, N., Mori, Y., Oswald, I.P. 2013. Deoxynivalenol impairs the immune functions of neutrophils. Mol. Nutr. Food Res., Doi:10.1002/ mnfr.201200755.

Häller, G.B., Munich, M., Kleijer, G., Mascher, F. 2008. Characterisation of kernel resistance against Fusarium infection in spring wheat by baking quality and mycotoxin assessments. Eur. J. Plant Pathol. 120:61-68.

He, J., Zhou, T., Young, J.C., Boland, G.J., Scott, P.M. 2010. Chemical and biological transformations for detoxifications of trichothecene mycotoxins in human and animal food chains: a review. Trends in Food Sci. \& Technol. 21:67-76.

Hietaniemi, V., Kontturi, M., Rämö, S., Eurola, M., Kangas, A., Niskanen, M., Saastamoinen, M. 2004. Contents of trichothecenes in oats during official variety, organic cultivation and nitrogen fertilization trials in Finland. Agricultural and Food Sci. 13:54-67. 
Imathiu, S.M., Edwards, S.G., Ray, R.V., Back, M.A. 2013. Fusarium langsethiae - a HT-2 and T-2 toxins producer that needs more attention. J. Phytopathol. 161:1-10.

Imathiu, S.M., Hare, M.C., Ray, R.V., Back, M., Edwards, S.G. 2010. Evaluation of pathogenicity and aggressiveness of $F$. langsethiae on oat and wheat seedlings relative to known seedling blight pathogens. Eur. J. of Plant Pathol. 126:203-216.

Infantino, A., Pucci, N., Conca, G., Santori, A. (2007). First report of Fusarium langsethiae on durum wheat kernels in Italy. Plant Disease 91:1362.

Lancova, K., Hajslova J., Kostelanska, M., Kohoutkova, J., Nedelnik, J., Moravcova, H., Vaniva, M. 2008. Fate of trichothecene mycotoxins during the processing: Milling and baking. Food Additives and Contaminants 25:650-659.

Langseth, W., Rundberget, T. 1999. The occurrence of HT-2 toxin and other trichothecenes in Norwegian cereals. Mycopathologia 147:157-165.

Lemmens, M., Scholz, U., Berthiller, F., Dall'Asta, C., Koutnik, A., Schuhmacher, R., Adam, G., Buerstmayr, H., Mesterházy, Á., Krska, R., Ruckenbauer, P. 2005. The ability to detoxify the mycotoxin deoxynivalenol colocalizes with a major quantitative trait locus for Fusarium Head Blight resistance in wheat. MPMI. 18:1318-1324.

Maresca, M. 2013. From the gut to the brain: journey and pathophysiological effects of the food-associated trichothecene mycotoxin deoxynivalenol. Toxins 5:784-820.

Miller, J.D. 2008. Mycotoxins in small grains and maize: Old problems, new challenges. Food Addit. Contam. 25:219-230.

Nazari, L., Pattori, E., Terzi, V., Morcia, C., Rossi, V. 2014. Influence of temperature on infection, growth, and mycotoxin production by Fusarium langsethiae and F. sporotrichioides in durum wheat. Food Microbiology 39:19-26.

Nightingale, M.J., Marchylo, B.A., Clear, R.M., Dexter, J.E., Preston, K.R. 1999. Fusarium Head Blight: Effect of fungal proteases on wheat storage proteins. Cereal Chem. 76:150-158.

Opoku, N., Back, M., Edwards, S.G. 2013. Development of Fusarium langsethiae in commercial cereal production. Eur. J. Plant. Pathol. 136:159-170.

Pascale, M., Haidukowski, M., Lattanzio, V.M.T., Silvestri, M., Ranieri, R., Visconti, A. 2011. Distribution of T-2 and HT-2 toxins in milling fractions of durum wheat. J. of Food Protection 74:1700-1707.

Pestka, J.J., Smolinski, A.T. 2005. Deoxynivalenol: toxicology and potential effects on humans. J. of Toxicology and Environmental Health Part. B. 8:39-69.

Quaranta, F., Amoriello, T., Aureli, G., Belocchi, A., D’Egidio, M.G., Fornara, M., Melloni, S., Desiderio, E. 2010. Grain yield, quality and deoxynivalenol (DON) contamination of durum wheat (Triticum durum Desf.): Results of National Networks in Organic and Conventional Cropping Systems. Ital. J. of Agronomy 4:353-366.

Quaranta, F., Belocchi, A., Fornara, M., Mazzon, V., Camerini, M., Cecchini, C., Gosparini, E., D’Egidio, M.G. 2013. Varietà di grano duro per le semine 2013 (The durum wheat cultivars suitable for sowing in the year 2013). L'Informatore Agrario, Suppl. 32:5-11.

Rocha, O., Ansari, K, Doohan, F.M. 2005. Effects of trichothecene mycotoxins on eukaryotic cells: A review. Food Addit. Contam. 22:369-378.

Russel, R., Paterson, M., Lima, N. 2010. How will climate change affect mycotoxin in food? Food Research International 43:1902-1914.

Santori, A., De Felice, S., Aureli, G., Scala, V., Belocchi, A., Infantino, A. 2010. Fusarium langsethiae in Italy: geographical distribution, pathogenicity and toxin production. Petria 20:459.

SCF 2002. Opinion on Fusarium toxins. Part 6: Group evaluation of T-2 toxin, HT-2 toxin, nivalenol and deoxynivalenol (http://www.europa.eu.int/comm/food/fs/sc/scf/out123_en.pdf).

Shephard, G.S. 2008. Impact of mycotoxins on human health in developing countries. Food Addit. Contam. 25:146-151.

Schmidt, H., Adler, A., Holst-Jensen, A., Klemsdal, S.S., Logrieco, A., Mach, R.L. 2004. An integrated taxonomic study of Fusarium langsethiae, Fusarium poae and Fusarium sporotrichioides based on the use of composite datasets. Int. J. Food Microbiol. 95:341-349. 
Terzi, V., Morcia, C., Faccioli, P., Faccini, N., Rossi, V., Cigolini, M., Corbellini, M., Scudellari, D., Delogu, G. 2007. Fusarium DNA traceability along the bread production chain. Int. J. of Food Sci. and Technol. 42:1390-1396.

Tittlemier, S.A., Gaba, D., Chan, J.M. 2013. Monitoring of Fusarium trichothecenes in Canadian cereal grain shipments from 2010 to 2012. J. Agr. and Food Chem. 61:7412-7418.

Torp, M., Adler, A. 2004. The European Sporotrichiella project: a polyphasic approach to the biology of a new Fusarium species. Int. J. of Food Microbiol. 95:241-245.

van der Fels-Klerx, H.J., Stratakou, I. 2010. T-2 toxin and HT-2 toxin in grain and in grain-based commodities in Europe: occurrence, factors affecting occurrence, co-occurrence and toxicological effects. World Mycotoxin Journal 3:349-367.

Váňová, M., Klem, K., Miša, P., Matušinsky, P., Hajšlová, J., Lancova, K. 2008. The content of Fusarium mycotoxins, grain yield and quality of winter wheat cultivars under organic and conventional cropping systems. Plant Soil Environ. 9:395-402.

Wu, Q., Dohnal, V., Huang, L., Kuča, K., Yuan, Z. 2010. Metabolic pathways of trichothecenes. Drug Metabolism Reviews 42:250-267.

Yazar, S., Omurtag, G.Z. 2008. Fumonisins, trichothecenes and zearalenone in cereals. Int. J. Mol. Sci. 9:20622090 .

Zain, M.E. 2011. Impact of mycotoxins on human and animals. J. of Saudi Chem. Soc. 15:129-144.

\section{Electronic Supplementary Material (ESM)}

Electronic Supplementary Material (ESM) associated with this article can be found at the website of CRC at http://www.akademiai.com/content/120427/

Electronic Supplementary Figure S1. Map of Italy showing the cultivation areas (left) and latitude and longitude of the locations (right) assayed

Electronic Supplementary Figure $S 2$. The positive samples (concentration $\geq$ LOD) percentage referred to the total samples (incidence \%) for DON and T2+HT2 toxins (three-year period, 2011-2013)

Electronic Supplementary Figure S3. The average and the highest concentrations (ppb) of DON and T2+HT2 toxins in positive samples (three-year period, 2011-2013)

Electronic Supplementary Figure S4. The box plot of DON concentration $(\mu \mathrm{g} / \mathrm{kg})$ and T2+HT2 concentration $(\mu \mathrm{g} / \mathrm{kg})$ of cultivars. Anomalous data or suspected outlie.rs are displayed as unfilled circles, outliers as filled 